\section{Delayed Toxicity of Radiostrontium in Monkeys}

IN a long-term experiment on the effects of low doses of radiostrontium, six monkeys have died following single injections of pure 'carrier-free' strontium-90 of less than $0.2 \mathrm{mc} / \mathrm{kgm}$. body-weight. The hæmatological findings, and the comparison of survival-times with those obtained in animals which received higher doses ${ }^{1}$, are noteworthy.

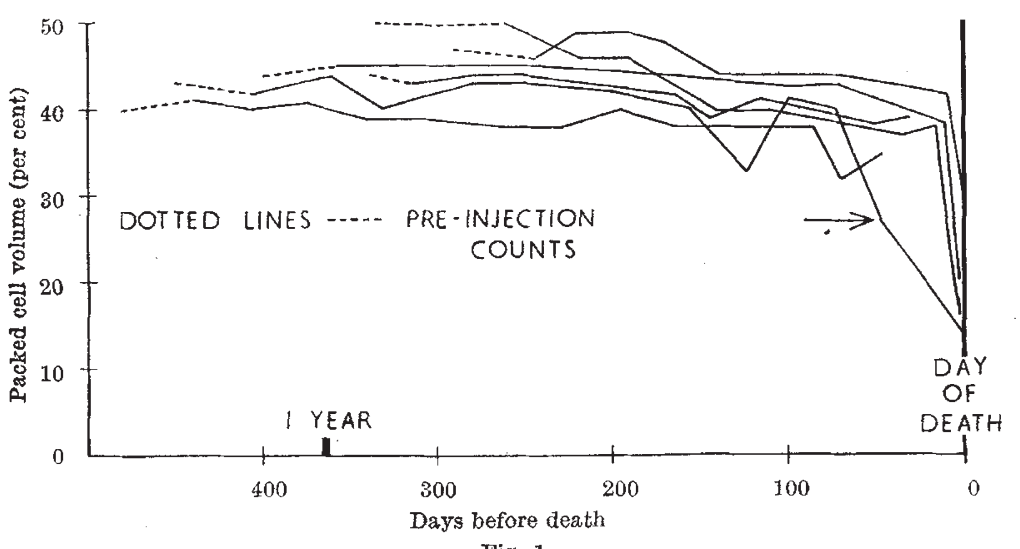

Fig. 1

The blood picture in the six animals did not seriously deteriorate following the injections until a sharp terminal fall shortly before death, as shown in the graph of packed cell volume (Fig. 1). In four of the animals, the hæmatological findings were within normal limits until two or three weeks before death, and in only one case was there any significant gradual decrease in red blood cell count and packed cell volume before the terminal drop. Only in one animal (marked $\rightarrow$ on Fig. 1) was a severe drop in white blood cells observed; the count fell from $13,000 / \mathrm{mm}^{3}$ 46 days before death, to $1,200 / \mathrm{mm}^{3}$ at death. The animals appeared in normal health until about a week before death.

In the three animals which were examined histologically, the most severe lesions were seen, as expected, in bone marrow, reproductive organs, and reticulo-endothelial system. Damage in the latter

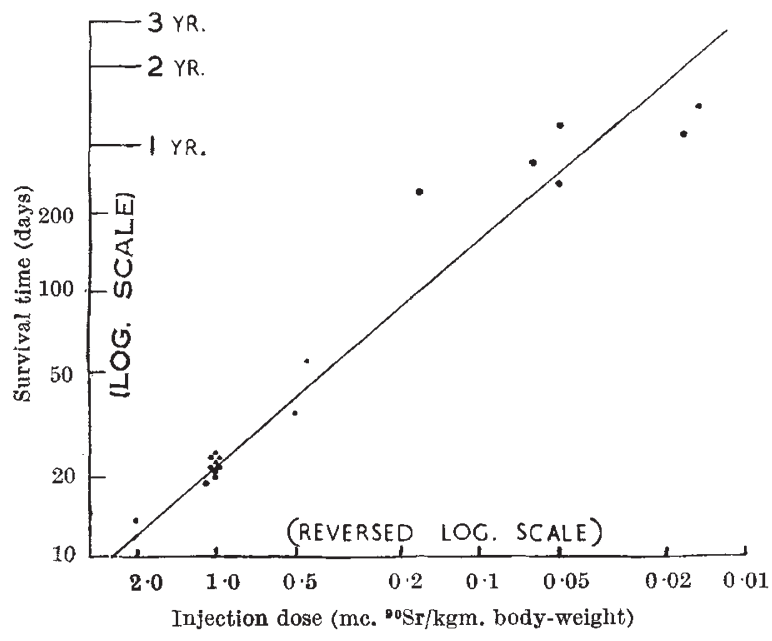

Fig. 2 varied widely in the different animals. In one animal the spleen exhibited extreme atrophy, whereas in another the germinal centres were large and prominent with numerous mitotic figures present.

It is noteble that the times of survival for the six monkeys fit the straight-line extrapolation of the graph of survival times for the thirteen 'high-dose' monkeys (Fig. 2).

All the monkeys were kept on a good mixed diet of medium calcium content, and the radiostrontium content of their fæces and urine was assayed. The logarithm of daily excretion was plotted against the logarithm of time $T$ (days) after injection, and from the straight line for the whole period the relationship

$$
E \text { per cent }=10 T^{-1.0}
$$

was deduced for the daily excretion, $E$ per cent, of the injection dose. The carcass at death contained an average of 30 per cent of the injection dose.

The investigation is continuing, and we intend to report elsewhere on the details of histopathology, hæmatology and radioactivity assays. Observations to date on the twelve surviving monkeys do not conflict with these preliminary findings.

Acknowledgments are due to Mr. A. H. Booth and the College authorities, and to the Medical Research Council.

G. M. EDINGTON*

J. M. JuDD ${ }^{\dagger}$

A. H. WARD

University College of the Gold Coast, Achimota. Oct. 18.

* of the Medical Research Institute, Korle Bu, Gold Coast. + Now with Department of Tsetse Control, Gold Coast.

The first eight of the thirteen 'high-dose' deaths were reported in Nature. 172, 122 (1953).

\section{Action of lonizing Radiations on Catalase in Presence of Cysteine, Cystine and Glutathione}

ForssBeng ${ }^{1}$ reported that eysteine and glutathione did not protect catalase against inactivation by $\mathrm{X}$-rays, but on the contrary increased the radiation effect on the enzyme. Most organic substances act as protectors when added as a second solute to the solution of the primary solute. Since cysteine and glutathione have been used in protection experiments in vivo ${ }^{2,3}$ and in vitro ${ }^{4,5}$ it was decided to re-investigate the inactivation of catalase by irradiation, in view of the apparently exceptional nature of the effect of these substances.

Two types of radiation have been used: $\gamma$-rays from cobalt-60, and high-energy electrons from a linear electron accelerator. Beef liver catalase was irradiated alone and in the presence of cysteine, cystine and glutathione (-SH), and the resultant effects on the enzymatic activity, electrophoretic and chromatographic behaviour and on the ultra-violet absorption were examined.

Doses up to $93 \times 10^{6} \mathrm{ergs} / \mathrm{gm}$. were used, and the catalase concentration varied from $2.25 \times 10^{-4} \mathrm{gm}$. $\mathrm{ml}$. to $4.45 \times 10^{-3} \mathrm{gm}$. $/ \mathrm{ml}$. Irradiation was carried out in air, oxygen and nitrogen at $p H \mathbf{H} \cdot \mathbf{4}$. 